\title{
A vítima de crimes e o Tribunal Penal Internacional: um modelo irrefutável para o legislador interno
}

\author{
Crime victim and International Criminal Court: \\ an undeniable model to the lawmaker
}

\section{Teresa Lancry Robalo ${ }^{1}$}

Universidade de Macau - Macau, China

teresaso@um.edu.mo

http://orcid.org/0000-0001-5449-063X

\begin{abstract}
Resumo: O presente trabalho pretende analisar o nível de tutela conferida à vítima pelo Estatuto de Roma, que criou o Tribunal Penal Internacional, o qual abarca tanto uma vertente substantiva como processual, tendo levado em linha de conta os Estatutos, bem como as decisões tomadas pelos Tribunais Penais Internacionais ad hoc para a ex-Jugoslávia e para o Ruanda. Sucede, porém, que estes pecavam por não preverem um verdadeiro modelo em prol da vítima, pelo que o Estatuto de Roma, conjugado com o seu Regulamento de Procedimento e Prova, veio aditar um conjunto de medidas cruciais que visam proteger as vítimas e testemunhas, dar-Ihes a possibilidade de participarem no processo e, ainda, garantir a reparação. Revela-se, pois, como um paradigma a ser levado em linha de conta pelo legislador interno, independentemente de o respetivo Estado ser ou não parte deste instrumento de Direito Internacional. Concluímos que o papel desempenhado pela comunidade internacional nesta chamada de atenção para a vítima deve ser levado em linha de conta em sede interna permitindo assim, com Nils
\end{abstract}

1 Professora Auxiliar da Faculdade de Direito da Universidade de Macau. Doutora em Direito. Membro da World Society of Victimology, do European Forum for Restorative Justice, da Associação Internacional de Criminologia de Língua Portuguesa, do Victim Support Europe, da Asian Criminological Society e da European Society of Criminology. Antiga investigadora externa do extinto INTERVICT, Universidade de Tilburg, Holanda. O presente trabalho leva em linha de conta um dos temas abordados na nossa tese de doutoramento intitulada "O estatuto da vítima de crimes e o princípio da presunção de vitimização", não publicada. 
Christie, que à vítima seja devolvido um conflito que é o seu. $\mathrm{O}$ presente estudo emprega uma metodologia qualitativa, atendendo essencialmente à doutrina e partindo da análise da inovação trazida pelo Tribunal Penal Internacional sobre esta temática. A hipótese que nos orienta reside na assunção de que o modelo apresentado pelo Estatuto de Roma em prol das vítimas tem potencial para ser levado em consideração pelo legislador interno.

Palavras-chave: Estatuto de Roma; Participação; Proteção; Reparação; Tribunal Penal Internacional; Vítima.

ABSTRACT: This paper aims at having a closer look to the level of protection afforded by the Rome Statute to crime victims, as well by its Rules of Procedure and Evidence. The Rome Statute, which encompasses both substantial and procedural norms, has taken the Statutes and the decisions adopted by the ad hoc International Criminal Tribunals for ex-Yugoslavia and Rwanda. However, the latter did not provide a clear model that aimed at victims' protection. Therefore, Rome Statute and its Rules of Procedure and Evidence added a set of central measures that aim at protecting victims and witnesses, giving them the opportunity to take part in the process and granting them proper reparation. It shows up as being a paradigm to be taken into account by the internal legislator, even if the State is not a member of the Rome Statute. Hence, the role played by the international community in this regard must be taken into account by the legislator, allowing the victim to regain a conflict that indeed belongs to him/her, as previously argued by Nils Christie. This study makes use of a qualitative methodology, essentially taking literature into deep consideration and starting from the study of the innovation brought by the International Criminal Court on this matter. It is the author's aim to emphasize its importance as a potential model to be offered to the national legislator. Our hypothesis relies on the assumption that the model created by the Rome Statute towards victims has the potential to be considered by national legislator.

KeY words: International Criminal Court; Participation; Protection; Reparation; Rome Statute; Victim.

\section{INTRODUÇÃO}

A comunidade internacional tem-se preocupado sobremaneira com as vítimas de crimes, seja em termos globais, seja em sede regional. 
Sem embargo dos vários instrumentos de Direito Internacional que não podem ser descurados a este respeito, como por exemplo a Declaração sobre Princípios Básicos de Justiça para as Vítima de Crimes e de Abuso de Poder de 1985, ou na Recomendação do Conselho da Europa sobre a posição da vítima no âmbito do Direito Penal e Processual Penal, do mesmo ano, sem esquecer a Decisão-quadro da União Europeia de 2001, entretanto substituída pela Diretiva de 2012 ou, ainda, a Recomendação do Conselho da Europa sobre Assistência às vítimas de crimes, de 2006, atendemos por ora em concreto ao papel desempenhado pelo Estatuto de Roma e pelo Regulamento de Procedimento e Prova, pois que estes revelam um cuidado particular e abrangente para com a vítima de crimes, salvaguardando três direitos em concreto: o direito à participação, à proteção e à reparação. São justamente esses direitos que ocuparão doravante a nossa análise, com vista a descortinar o seu efetivo alcance.

\section{O Tribunal Penal Internacional - breVe Referência histórica}

Antes de avançarmos para a análise do papel que as vítimas desempenham no âmbito de um processo em curso perante o Tribunal Penal Internacional (TPI), cumpre apresentar sumariamente as raízes históricas do seu surgimento. Para o que nos interessa, acompanhamos a doutrina que salienta que, no que se prende às vítimas de crimes, o funcionamento deste Tribunal permanente sempre poderá servir de modelo a diversas ordens jurídicas internas - sejam ou não partes do referido Estatuto ${ }^{2}$.

2 Na exposição da matéria que se segue levaremos em consideração, entre outros posteriormente citados, William A. Schabas, An Introduction to the International Criminal Court, 4. ${ }^{\text {a }}$ edição, Cambridge University Press, 2011.

Para mais desenvolvimentos sobre o tema vide, entre outros e para além do autor citado, Maria Leonor Esteves Assunção, "O Tribunal Penal Internacional Permanente e o mito de Sísifo", in Revista Portuguesa de Ciência Criminal, Coimbra Editora, Ano 8, fascículo 1. ${ }^{\circ}$, Janeiro-Março de 1998, p. 27-36, Jorge Bacelar Gouveia, Manual de Direito Internacional Público, 3. ${ }^{\text {a }}$ edição, Almedina, 2007, Georghios M. Pikis, The Rome Statute for the International Criminal Court - analysis of the Statute, the Rules of Procedure and Evidence, the Regulations of the Court and supplementary instruments, Leiden, Boston, Martinus Nijhoff Publishers, 2010, Luke Moffett, "Releasing Justice for victims before the International Criminal Court", in ICD Brief 6, September 
Foi necessário percorrer um longo caminho para que surgisse, na esfera jurídica internacional, um Tribunal dotado de jurisdição para julgar crimes de guerra, de genocídio, contra a humanidade ou de agressão. Efetivamente, conforme esclarece William A. Shabas, apesar dos esforços no sentido da criação de um Tribunal Penal Internacional permanente, não foi possível atingir esse desiderato entre as duas Grandes Guerras mundiais, pese embora alguns jurisconsultos da Associação Internacional de Direito Penal tivessem preparado um Tratado da Liga das Nações com

2014, disponível em http://www.internationalcrimesdatabase.org/upload/ documents/20140916T170017-ICD\%20Brief\%20-\%20Moffett.pdf, GIUSEPPE ZAGO, "The role of victims at the International Criminal Court: legal challenges from the tension between restorative and retributive justice", in Diritto Penale Contemporaneo, Milão, 2014, disponível em https://www.penalecontemporaneo.it/upload/1415744172ZAGO_2014.pdf, FionA McKAY, "The International Criminal Court: A New Role for Victims in International Criminal Proceedings", in Adalah's Newsletter, Volume 15, Julho de 2005, disponível em https://www.adalah.org/uploads/oldfiles/newsletter/eng/ jul05/ar1.pdf, Mina Rauschenbach e Damien Scalia, "Victims and international criminal justice: a vexed question?", in International Review of the Red Cross, Volume 90, número 870, Junho de 2008, disponível em https:// www.adalah.org/uploads/oldfiles/newsletter/eng/jul05/ar1.pdf, VÉRONIQUE GINGRAS-GAUTHIER, "Les victimes devant la Cour pénale internationale: espoirs et défis", in Quid Justitiae, 2013, disponível em https://www.quidjustitiae.ca/blogue/les-victimes-devant-la-cour-penale-internationale-espoirs-et-defis, Elisabeth Baumgartner, "Aspects of victim participation in the proceedings of the International Criminal

Court", in International Review of the Red Cross, Volume 90, número 870, Junho de 2008, disponível em http://www.corteidh.or.cr/tablas/R21692.pdf, Almudena Pérez Vizán, "Las víctimas ante la Corte Penal Internacional ¿El final del oxymoron víctimas-justicia internacional?", disponível em http:// www.corteidh.or.cr/tablas/r26828.pdf, NATACHA BRACQ, "Analyse comparée de la participation des victims devant la Cour Pénale Internationale et devant les juridictions pénales des pays de tradition romanogermanique", in La Revue des droits de l'homme, 4, 2013, Varia, disponível em https://revdh. revues.org/316, Claire Garbett, "The International Criminal Court and restorative justice: victims, participation and the processes of justice", in Restorative Justice. An International Journal, Agosto de 2017, disponível em http://www.tandfonline.com/doi/full/10.1080/20504721.2017.1339953, Human Rights Center, The victims' Court? A Study of 622 Victim Participants at the International Criminal Court, 2015, disponível em https://reliefweb.int/sites/reliefweb.int/files/resources/VP_report_2015_final_full2. pdf, todos acedidos pela última vez a 19 de Novembro de 2017. 
esse propósito o qual, no entanto, nunca chegou a entrar em vigor devido ao escasso número de ratificações ${ }^{3}$.

Nos últimos anos da Segunda Guerra Mundial, os Aliados afirmaram a sua determinação em julgar os nazis pelos crimes de guerra, na Declaração de Moscovo de 1943. No que prende à Europa, o acordo para o julgamento e punição dos mais relevantes criminosos de guerra do Eixo Europeu e para a criação da Carta do Tribunal Militar Internacional foi formalmente adotado a 8 de Agosto de 1945. A jurisdição do Tribunal dizia respeito a crimes contra a paz, crimes de guerra e crimes contra a humanidade, levantando-se ainda o problema da inexistência de lei prévia que incriminasse esses atos, o que foi contornado por muitos que invocaram, nomeadamente, o Tratado de Sèvres de 1920, um Tratado de paz que surgia na decorrência das perseguições que os arménios tinham sido alvo desde $1915^{4}$.

Devido a essa lacuna à escala internacional, que fazia com que se remetessem os atos de genocídio aos crimes contra a humanidade, a 11 de Dezembro de 1946 foi adotada a Resolução n. ${ }^{\circ} 96$ (I) da Assembleia Geral das Nações Unidas declarando o genocídio como um crime contra o direito internacional e apelando à elaboração de uma convenção sobre esta matéria, a qual acabou por ser adotada em 1948 e entrou em vigor na ordem jurídica internacional a 12 de Janeiro de 1952.

De salientar, ainda, que foi criada uma Comissão de Direito Internacional, sob os auspícios da Assembleia Geral da ONU, com vista a preparar um Estatuto do Tribunal Penal Internacional e ainda um Código de Crimes contra a paz e a segurança da humanidade, a qual não teve progressão devido à Guerra Fria. Enquanto o projeto de Estatuto do TPI continuava a ser estudado e elaborado, surgiram dois Tribunais Penais Internacionais ad hoc: um para a ex-Jugoslávia, em 1993, e outro para o Ruanda, em 1994, ambos criados por Resolução do Conselho de Segurança. Segundo William Shabas, estes Tribunais apresentavam várias semelhanças, desde um Estatuto idêntico, um mesmo Procurador numa

3 William A. Schabas, An Introduction to the International Criminal Court cit., p. 5.

4 William A. Schabas, An Introduction to the International Criminal Court cit., p. 6-16. 
primeira fase e a mesma composição da instância de recurso os quais, aliados ao trabalho que vinha sendo desenvolvido pela Comissão de Direito Internacional, desempenharam um papel fundamental em termos de antecedentes jurídicos para o Estatuto de Roma do TPI ${ }^{5}$.

No seguimento das Resoluções da Assembleia Geral da ONU de 1996 e de 1997, uma conferência diplomática de plenipotenciários para a criação de um TPI teve lugar em Roma, a 15 de Junho de 1998, para onde mais de 160 Estados enviaram delegados, tendo ainda dela participado várias Organizações Internacionais e organizações não-governamentais. Essa conferência teve a duração de um mês até ao surgimento da versão final do Estatuto, incorporando já tanto disposições de direito penal substantivo, como de direito processual penal. Dos Estados presentes, 120 votaram a favor da proposta de Estatuto, 21 abstiveram-se e 7 votaram contra, entre os quais os Estados Unidos da América, Israel e a República Popular China ${ }^{6}$.

Será de salientar, na esteira de Trumbull, por sua vez citado pela UNODC, que o conjunto de soluções em prol das vítimas que encontramos no Estatuto de Roma, sejam elas de cariz substantivo ou adjetivo, visaram justamente dar cobro às críticas que eram tecidas aos Tribunais ad hoc anteriormente citados que pecavam no que concerne à sua tutela ${ }^{7}$.

Somos da opinião que nada impede que o texto do Estatuto de Roma, bem como a experiência acumulada desde a entrada em funcionamento do TPI, nomeadamente no que se prende ao conjunto de direitos conferidos às vítimas de crimes, sejam levados em consideração por ordenamentos jurídicos que não façam parte do Estatuto de Roma, pois os dispositivos que se prendem às vítimas de crimes assumem uma tal relevância que é digna da sua apreciação e eventual adoção na ordem jurídica interna.

5 William A. Schabas, An Introduction to the International Criminal Court cit., p. 6-16.

6 William A. Schabas, An Introduction to the International Criminal Court cit., p. 16-22.

7 Charles P Trumbull IV, The victims of victim participation in international criminal proceedings. Michigan Journal of International Law, vol. 29, 2008, p. 778. apud https://www.unodc.org/e4j/en/crime-prevention-criminal-justice/module-11/key-issues/8--victims-of-crime-and-international-law.html, acedido pela última vez a 9 de Março de 2020. 


\section{O Estatuto de Roma e o seu modelo paradigmático em prol DAS VÍTIMAS DE CRIMES}

O Estatuto de Roma veio, conforme previsto no seu artigo 1. ${ }^{\circ}$, criar o Tribunal Penal Internacional, enquanto instituição permanente com vista a julgar "as pessoas responsáveis pelos crimes de maior gravidade com alcance internacional”, sendo complementar às jurisdições penais nacionais. Foi adotado em Roma a 17 de Julho de 1998, mas só entrou em vigor a 1 de Julho de 2002 quando, por respeito ao seu artigo $126 .{ }^{\circ}$, n. $^{\circ} 1$, decorreu o período aí previsto contado após o depósito do 60..$^{\circ}$ instrumento de ratificação, de aceitação, de aprovação ou de adesão.

Nos termos deste tratado, o TPI passou a ter jurisdição para julgar, numa lógica de complementaridade e de subsidiariedade relativamente aos Estados partes ou com base num acordo ad hoc quanto aos Estados que não sejam partes (nos termos do artigo 12. ${ }^{\circ}$ do Estatuto de Roma), as pessoas indiciadas por crimes de guerra, crimes contra a humanidade, crimes de genocídio ou ainda crimes de agressão.

A doutrina tem feito questão de salientar que não restam dúvidas no sentido de que os Estados pretenderam reconhecer uma posição especial às vítimas e testemunhas, o que resulta da análise do Estatuto de Roma mas também das Regras de Procedimento e Prova ${ }^{8}$. O motivo deste

8 Para além do Regulamento do TPI e do Regulamento da Secretaria do TPI. Segundo Paulina Vega GonzÁlez, conseguem encontrar-se 115 referências às vítimas no cômputo dos quatro instrumentos referidos. In "O papel das vítimas nos procedimentos perante o Tribunal Penal Internacional: seus direitos e as primeiras decisões do Tribunal", in Revista Internacional de Direitos Humanos, vol. 3, n. ${ }^{\circ}$ 5, São Paulo, Dezembro 2006, p. 21. Também Rianne LETSCHERT salienta a importância que o Estatuto de Roma deu às vítimas de crimes, a tal ponto que poderá ser considerado como "o melhor modelo até agora para reduzir os riscos de vitimização secundária". Nomeadamente, a autora salienta a necessidade de que os membros do Tribunal, incluindo magistrados, que lidem com vítimas de crimes, tenham experiência nesse campo, nomeadamente no que diz respeito a vítimas de crimes sexuais. In RianNe LETSCHERT, "International Initiatives and Activities Focusing Specifically on Victims of Terrorism, Including Existing International Instruments", in Assisting Victims of Terrorism, Editado por Rianne Letschert, Ines Staiger e Antony Pemberton, Springer, 2010, p. 39. No mesmo sentido, Luke Moffett, "Releasing Justice for victims before the International Criminal Court" cit., p. 5, salientando inclusive que "a justiça para as vítimas tem sido expressa como a 
cuidado prende-se com o reconhecimento da situação de vulnerabilidade em que aquelas se encontram?.

De facto, o Estatuto visa proteger as vítimas e as testemunhas aquando da sua participação no processo, o que resulta claramente do seu artigo $68 .^{\circ}$, sendo que o TPI deve prover à proteção da sua vida privada $\mathrm{e}$ dignidade, o que é mais premente quando os casos envolverem crimes de natureza sexual ou crianças, podendo nesses casos abrir-se uma exceção à regra da publicidade da audiência.

Às vítimas é reconhecido o direito de expressarem as suas opiniões, distinguindo-as de meras testemunhas (vide, a este respeito, os artigos 89 a 93 das Regras de Procedimento e Prova do Tribunal Penal Internacional) ${ }^{10}$. É de facto necessário dar às vítimas a possibilidade de "fazerem o seu luto" sendo certo que, para elas, será amiúde mais importante expressar o que lhes vai na alma do que receber uma compensação monetária ${ }^{11}$. Mas é, contudo, evidente a importância da indemnização que é claramente assegurada nos termos do artigo $75 .^{\circ}$ do Estatuto, ao qual voltaremos infra.

Segundo a doutrina, com a qual concordamos na íntegra, a questão da tutela dos direitos das vítimas perante o TPI revela-se "num dos temas mais inovadores" que resultam do Estatuto de Roma, consubstanciando

razão de ser do Tribunal Penal Internacional”, reforçando ainda que o Estatuto de Roma adotou uma abordagem orientada para as vítimas.

9 A relevância dada às vítimas pelo TPI é igual e nomeadamente referida, de entre diversos outros autores, por Robert A. JERIN e LAURA J. MORIARTy, The victims of crime, New Jersey, Pearson, 2010, p. 264, Gilbert Bitti, "As vítimas perante o Tribunal Penal Internacional. Participação no processo", in Actas da Conferência Internacional de Processo Penal, "Os desafios do Séc. XXI”, Macau, Centro de Estudos Jurídicos e Judiciários, 2007, p. 329-352 ou SAM GARKAWE, "Have recent changes designed to benefit victims of international crimes added to the legitimacy of international criminal justice?", in International Criminal Justice. Legitimacy and Coherence, Cheltenham e Northampton, Editora Edwar Elgar, 2012, p. 269-303.

10 Teresa Lancry A. S. Robalo, "Vítimas de terrorismo e justiça restaurativa - análise da questão tendo a Lei n. ${ }^{0}$ 3/2006 sobre a prevenção do terrorismo (Macau) em consideração”, em vias de publicação, 2019, p. 5 da versão não publicada.

11 Teresa Lancry A. S. Robalo, Justiça Restaurativa. Um Caminho para a Humanização do Direito, Lisboa, Editorial Juruá, 2012, p. 89-109 
até "um dos maiores avanços da justiça penal internacional" ${ }^{2}$. Não esqueçamos o próprio preâmbulo do Estatuto, onde pode ler-se que “(...) no decurso deste século, milhões de crianças, homens e mulheres têm sido vítimas de atrocidades inimagináveis que chocam profundamente a consciência da humanidade”. A vivacidade com que as vítimas estavam na mens legis aquando da redação do Estatuto em apreço é inclusivamente salientada pela UNODC ${ }^{13}$.

Por seu turno, as Regras de Procedimento e Prova do TPI preveem um conjunto de medidas que visam a proteção das vítimas e das testemunhas, sendo de atender, em concreto, ao seu artigo $88 .^{\circ}$ onde se prevê a possibilidade de serem implementadas medidas especiais, nomeadamente de modo a facilitar o depoimento de vítimas ou testemunhas traumatizadas, crianças, pessoas idosas ou vítimas de violência sexual, em decorrência do disposto no artigo $68 .^{\circ}$ do Estatuto de Roma.

Ademais, este mesmo Regulamento de Procedimento e Prova abarca um conjunto de medidas que visam dar às vítimas a já supra referida possibilidade de participarem no procedimento (artigos $89 .^{\circ} \mathrm{a}$ 93. ${ }^{\circ}$ ). Saliente-se que as vítimas podem escolher um representante legal mas, se estivermos perante um número significativo de vítimas, pode inclusivamente o Tribunal requerer que indiquem um único ou alguns representantes legais comuns ${ }^{14}$. Prevê-se ainda que a Secretaria do Tribunal possa dispensar assistência financeira apropriada às vítimas de modo a pagar os honorários a um representante legal.

12 Paulina Vega González, “O papel das vítimas nos procedimentos perante o Tribunal Penal Internacional (...)" cit., p. 19. Também citado no nosso "Vítimas de terrorismo e justiça restaurativa (...)" cit.

13 In: https://www.unodc.org/e4j/en/crime-prevention-criminal-justice/module-11/key-issues/8--victims-of-crime-and-international-law.html, acedido pela última vez a 9 de Março de 2020.

14 Esse representante legal deve preencher as características previstas no artigo $22 .^{\circ}$, n. ${ }^{\circ} 1$ destas Regras, por remissão do n. ${ }^{\circ} 6$ do seu artigo $90 .^{\circ}$. Nomeadamente, deve ter competências específicas em sede de direito internacional ou criminal, bem como experiência adequada como magistrado, advogado ou semelhante. Deve ainda ter um conhecimento excelente e ser fluente em pelo menos uma das línguas usadas pelo TPI. Pode, ainda, ser assistido por outras pessoas como por exemplo por professores de direito com conhecimento relevante - tradução livre do artigo 22. ${ }^{\circ}$, n. ${ }^{\circ} 1$ das Regras de Procedimento e Prova. 
De salientar é ainda, a título por ora introdutório, a expressa previsão do direito à reparação das vítimas conforme consta do já citado artigo $75 .^{\circ}$ do Estatuto de Roma (artigos $94 .^{\circ}$ a $99 .^{\circ}$ do supra referido Regulamento).

De acordo com Maria Leonor Esteves, os direitos de intervenção no processo, de proteção das vítimas e de reparação revelam-se como conceitos nucleares da chamada "vitimologia da ação" ${ }^{15}$, sendo certo que os mesmos têm vindo a ser paulatinamente reforçados desde a aprovação da Resolução da Assembleia Geral das Nações Unidas n. ${ }^{\circ}$ $40 / 34$, de $1985^{16}$.

Segundo Luke Moffett, de notar será ainda o facto de se reconhecerem como principais necessidades das vítimas de crimes internacionais tanto aquelas que possam ser categorizadas de emocionais - como por exemplo a necessidade de lhes serem dados os meios necessários para beneficiarem de reabilitação psicológica face aos traumas vivenciados, o reconhecimento público da situação de vitimização ou ainda a tomada de medidas de proteção contra a revitimização - como, ainda, o desejo de receberem informação adequada sobre o motivo pelo qual foram vitimizadas ${ }^{17}$.

Algumas vítimas pretendem ainda que quem as vitimizara seja devidamente responsabilizado, sendo ainda certo que nem as necessidades das vítimas são absolutamente iguais (pois, se umas querem a punição do agente, outras quiçá preferem um outro tipo de abordagem face ao problema), nem essas necessidades assumem um carácter imutável no que concerne à mesma vítima, na medida em que as suas necessidades face ao crime sofrido poderão variar ao longo do tempo ${ }^{18}$.

15 Maria Leonor Esteves, "A vítima - da quase "invisibilidade" à obtenção de um "Estatuto". Ou do (inevitável) caminho para a humanização da ordem jurídico-penal", texto apresentado na Conferência organizada pela CIIDH Escola de Direito da Universidade do Minho, sob o tema "Novos desafios em torno da proteção da vítima: uma perspetiva multidisciplinar", 2 de Junho de 2017, p. 5.

16 Citado no nosso "Vítimas de terrorismo e justiça restaurativa (...)" cit.

17 Luke Moffett, "Releasing Justice for victims before the International Criminal Court" cit., p. 2-3.

18 Ibidem. 


\section{Direito À PARTICIPAÇÃo}

Após esta breve explanação em torno do regime jurídico respeitante às vítimas de crimes sob a jurisdição do TPI, cumpre regressar a Paulina Vega González que agrupa os direitos das vítimas em três núcleos fundamentais: o direito à participação, o direito à proteção e o direito à solicitação de reparação.

Dando, por ora, um especial destaque ao primeiro, refira-se que, no seguimento da exposição efetuada pela autora, esse direito "pode ser exercido em qualquer das etapas do procedimento perante o Tribunal", o que inclui as fases do inquérito, do processo ou da reparação, caso esta decorra em separado ${ }^{19}$.

De facto, o n. 3 do artigo $68^{\circ}$ do Estatuto de Roma estabelece que "se os interesses pessoais das vítimas forem afetados, o Tribunal permitir-lhes-á que expressem as suas opiniões e preocupações na fase processual que entenda apropriada e por forma a não prejudicar os direitos do acusado nem a ser incompatível com estes ou com a realização de um julgamento equitativo e imparcial (...)”.

No caso ICC-01/04-01/06-925, a propósito da questão de saber se as vítimas têm ou não o direito de participar automaticamente nas instâncias de recurso, o Juiz Georghios M. Pikis veio, na sua "opinião concorrente", efetuar uma interpretação do referido n. ${ }^{\circ} 3$ do artigo $68 .^{\circ}$ do Estatuto de Roma. Em termos históricos, o Magistrado entende que a base de uma tal disposição inovadora fora o artigo $6 .^{\circ}$, alínea b) da Declaração de Princípios Básicos de Justiça para as Vítimas de Crimes e de Abuso de Poder - Resolução 40/34, supra citada.

O Magistrado conclui que "o direito à participação das vítimas enunciado no artigo $68 .^{\circ}$, n. ${ }^{\circ} 3$ não tem paralelo imediato ou associação com a participação das vítimas em procedimentos penais quer na common law, como na Inglaterra e no País de Gales, onde não é reconhecido qualquer papel às vítimas no processo penal, exceto o direito de darem início à ação particular, quer no sistema Românico-Germânico, onde as vítimas [surgem] no papel de partes civis ou de assistentes e têm um

19 Paulina Vega González, "O papel das vítimas nos procedimentos perante o Tribunal Penal Internacional (...)” cit., p. 23. 
âmbito de participação alargado no processo penal. Nos Estados Unidos da América, a maioria dos Estados reconhece às vítimas de crimes o direito a participarem no processo penal (...)”, dando ainda os exemplos do Canadá, Austrália e Nova Zelândia ${ }^{20 / 21}$.

Com vista a alcançar uma correta interpretação do artigo $68 .^{\circ}$, n. ${ }^{\circ} 3$ do Estatuto de Roma - um Tratado - o Magistrado recorre aos artigos 31. ${ }^{\circ}$ e $32 .^{\circ}$ da Convenção de Viena sobre Direito dos Tratados de $1969^{22}$. Nomeadamente, o n. ${ }^{\circ} 1$ do artigo $31 .^{\circ}$ da Convenção de Viena estabelece que "um tratado deve ser interpretado de boa-fé, de acordo com o sentido comum a atribuir aos termos do tratado no seu contexto e à luz dos respetivos objeto e fim".

A versão em língua inglesa do n. ${ }^{\circ} 3$ do artigo $68 .^{\circ}$ do Estatuto de Roma é clara ao referir que "where the personal interests of the victims are affected, the Court shall permit their views and concerns to be presented and considered at stages of the proceedings determined to be appropriate by the Court (...)" (negrito nosso). Ou seja, e como bem refere Georghios M. Pikis, sempre que estejam em causa interesses pessoais das vítimas que possam ser afetados pelo processo, o Tribunal "deve" (estando obrigado a) "permitir que as suas opiniões e preocupações sejam apresentadas e consideradas" ${ }^{23}$.

No entanto, na opinião do Magistrado, as vítimas não chegam a ser consideradas "partes" no processo penal, nem lhes cabe fazer a prova da prática dos factos. O que o artigo 68. ${ }^{\circ}$ do Estatuto de Roma lhes permite cinge-se a poderem apresentar as suas "opiniões e preocupações" relativas aos seus interesses pessoais quanto às perdas ou danos que tenham sofrido em virtude do crime que fora sobre elas praticado ${ }^{24}$.

20 ICC-01/04-01/06-925, 13/6/2007, p. 16-17, disponível em https://www. icc-cpi.int/iccdocs/JUDSUMM/JSV_ICC_0104_0106_925.pdf, acedido pela última vez a 9 de Março de 2020. Tradução livre.

21 Georghios M. Pikis, The Rome Statute for the International Criminal Court cit., p. 293.

22 ICC-01/04-01/06-925, 13/6/2007, p. 17.

23 Georghios M. Pikis, The Rome Statute for the International Criminal Court cit., p. 19.

24 Georghios M. Pikis, The Rome Statute for the International Criminal Court cit., p. 20. 
Vimos acima que as vítimas podem manifestar-se nos termos expostos em qualquer fase do processo, desde que o Tribunal considere o momento oportuno (artigo $68 .^{\circ}$, n. $^{\circ} 1$ do Estatuto de Roma). Como tal, poderão por exemplo fazê-lo após a fase probatória na medida em que considerem que as provas apresentadas tenham reflexos nos seus interesses pessoais. Todavia, por respeito ao princípio da igualdade de $\operatorname{armas}^{25}$ e de outras disposições do Estatuto, a última palavra deverá caber ao arguido ${ }^{26}$.

A relevância atribuída às vítimas perante a jurisdição criminal internacional é igualmente referida, entre outros, por William A. Shabas que salienta a criação da Victims and Witnesses Unit junto da Secretaria do $\mathrm{TI}^{27}$. O autor refere que o número de vítimas que têm manifestado o seu interesse em participar no processo tem vindo a aumentar. Nomeadamente, "em Outubro de 2008 a Secretaria do TPI anunciou que 960 vítimas tinham requerido a sua participação no processo (...) o que foi admitido pelo tribunal em 126 casos"28.

A instância de julgamento no processo ICC-01/04-01/06 decidiu, a 8 de Abril de 2009, que o artigo 85. ${ }^{\circ}$ das Regras de Procedimento e Prova abrange igualmente quem tenha sofrido um dano direto em decorrência do crime. Por conseguinte, considerou estarem aqui incluídas quer as vítimas "diretas", quer as "indiretas", definindo as primeiras como aquelas "cujo prejuízo seja o resultado da comissão de um crime sob a jurisdição do Tribunal" e estas últimas como "aquelas cujo prejuízo seja o resultado do dano sofrido pelas vítimas diretas”29.

William A. Shabas esclarece que o conceito de vítimas indiretas engloba, nomeadamente, “os pais das vítimas, quem tenha sofrido um prejuízo enquanto intervinha com o intuito de assistir as vítimas e crimes genericamente direcionados à população civil”. Todavia, o autor esclarece

25 Diríamos, antes, por força do princípio do contraditório.

26 Georghios M. Pikis, The Rome Statute for the International Criminal Court cit., p. 23.

27 William A. Shabas, An introduction to the International Criminal Court cit., p. 342 .

28 William A. Shabas, An introduction to the International Criminal Court cit., p. 348.

29 ICC-01/04-01/06 - 1813, Redacted version of "Decision on Indirect Victims", de 8/4/2009, parágrafo 44, p. 18. 
que "o conceito não se estende às pessoas que sofreram um prejuízo em resultado da conduta de outras vítimas, como por exemplo aquelas que são vitimizadas pelas crianças soldado" ${ }^{30}$.

A afirmação do autor supra citado carece ser contextualizada de modo a poder ser corretamente entendida. De facto, o TPI refere que não cabem no conceito de vítimas indiretas as pessoas que foram vitimizadas pelas crianças soldado, mas porque o caso que estava sob a sua apreciação prendia-se com a apreciação da culpa de quem alistara ou usara crianças para participarem ativamente nas hostilidades. Portanto, as vítimas da conduta do acusado eram precisamente as crianças soldado, para efeitos do caso em apreço. Como não cabem no conceito de "vítimas indiretas" aqueles que sofreram um dano em virtude da conduta de outras vítimas, não caberão aqui, para efeitos de casos como este, as vítimas de vítimas desses crimes $^{31}$.

Em suma, sobre o direito à participação da vítima junto do TPI, e embora não tenha sido reconhecida como verdadeiro sujeito processual, acabou por ver a sua posição processual bastante aproximada à do assistente em sede processual penal interna (nomeadamente em sistemas jurídicos como o português ou o de Macau). De facto, tem a mesma a possibilidade de ser ouvida no decurso da audiência de julgamento, podendo fazer-se representar por advogado o qual pode, nomeadamente, interrogar o arguido ou inquirir testemunhas e peritos, podendo ainda carrear elementos de prova ${ }^{32}$.

\section{DiReito À REPARAÇÃo}

Para além do direito à participação no processo, conferido às vítimas de crimes sob a jurisdição do TPI, o Estatuto de Roma também

30 William A. Shabas, An introduction to the International Criminal Court cit., p. 352 .

31 ICC-01/04-01/06 - 1813, 8/4/2009 Redacted version of "Decision on Indirect Victims" cit., parágrafo 52, p. 21, disponível em https://www.icc-cpi.int/ CourtRecords/CR2009_02492.PDF, acedido pela última vez a 10 de Março de 2020.

32 Maria Leonor Esteves, "A Vítima - da quase "invisibilidade" à obtenção de um "Estatuto" (...)" cit., p. 10. 
se reporta ao direito que lhes assiste à reparação dos danos sofridos. De tal modo o regime é inovador na cena internacional, que nomeadamente Conor McCarthy defende que poderia servir de modelo não só para outros textos internacionais, como internamente ${ }^{33}$.

$\mathrm{O}$ artigo $75 .^{\circ}$ do Estatuto de Roma prevê um direito à reparação em favor das vítimas. No seu n. ${ }^{0} 1$ prevê-se que "o Tribunal estabelecerá princípios aplicáveis às formas de reparação, tais como a restituição, a indemnização ou a reabilitação, que hajam de ser atribuídas as vítimas ou aos titulares desse direito (...)".

Tal como defende Conor McCarthy, também nós entendemos que a reparação não apresenta um carácter punitivo, mas sim civilístico. Para isso contribui não só a sua localização sistemática no Estatuto, precisamente antes das normas respeitantes à aplicação da pena, como o facto de não constar do leque de sanções aplicáveis ao agente nos termos do artigo 77. ${ }^{\circ}$. Tendo o conceito uma abrangência meramente civil, deverá ser entendido como "compensação pela perda" ou a "correção de um dano"34. Nesta perspetiva, e numa ótica comparatística, o direito à reparação constante do artigo $75 .^{\circ}$ do Estatuto de Roma apresenta a mesma lógica do direito interno à indemnização, que se funda na necessidade de tornar o lesado in demne.

Neste contexto, o próprio TPI veio esclarecer que o dano apto a ser reparado tanto pode ser "material, físico ou psicológico" 35 , abrangendo assim o dano patrimonial e o não patrimonial. No entanto, e na esteira de Conor McCarthy, esta referência é demasiado vaga precisando, pois, ser especificada.

Note-se ainda que, quando o Tribunal faz esse reparo a propósito das diversas formas de dano, retoma a distinção entre vítimas diretas e indiretas e refere que "o dano sofrido por uma vítima em decorrência da comissão de um crime sob a jurisdição do Tribunal pode dar origem ao

33 Conor McCarthy, Reparations and Victim Support in the International Criminal Court, Cambridge University Press, 2012, p. 329-346.

34 Conor McCARThy, Reparations and Victim Support in the International Criminal Court cit., p. 79.

35 ICC-01/04-01/06, Judgement on Victim's Participation, parágrafo 32, p. 13 e 14 . 
dano sofrido por outras vítimas", dando o exemplo das crianças soldado como vítimas diretas e dos seus pais como vítimas indiretas ${ }^{36}$.

Por seu turno, o dano não patrimonial abrange nomeadamente os casos de morte, ofensa à integridade física e psíquica (entre outros direitos de personalidade), sofrimento, angústia e dor em decorrência do crime ${ }^{37}$. Quanto à morte, uma questão controvertida e ainda não esclarecida pela jurisprudência do Tribunal consiste em saber se o direito à indemnização que assiste aos familiares da vítima inclui tão-somente o sofrimento por estes sentido pela perda da pessoa querida ou, também, o dano sofrido pela própria vítima pelo facto de lhe ter sido retirada a sua própria vida (para além dos danos imediatamente antecedentes) ${ }^{38}$.

Tal como no direito interno, também em sede internacional o direito à reparação dependerá do preenchimento de um determinado número de requisitos cumulativos. Já vimos que deve naturalmente existir um dano - patrimonial ou não.

Um segundo requisito será o nexo de causalidade. De facto, o próprio artigo $85 .^{\circ}$, alínea a) das Regras de Procedimento e Prova define as vítimas como sendo aquelas pessoas que sofreram um dano em consequência de um facto criminoso sob a jurisdição do TPI. Para além de uma causalidade de facto, no sentido de ter de se demonstrar que uma determinada conduta foi a causadora do dano sofrido, é necessário acrescentar-lhe um elemento jurídico com vista a limitar essa factualidade (no fundo, no sentido de impedir uma imputação ad infinitum) que consiste em exigir que o dano esteja diretamente ligado ao facto, para além dos elementos proximidade e previsibilidade ${ }^{39}$.

Obviamente que não poderá ser olvidada a necessidade de existência de um facto ilícito que consubstancie um crime à luz do Estatuto de Roma, para que daí derive a responsabilização a que nos reportamos.

36 Ibidem.

37 Conor McCARThy, Reparations and Victim Support in the International Criminal Court cit., p. 110-123.

38 Conor McCARthy, Reparations and Victim Support in the International Criminal Court cit., p. 110-111.

39 Conor McCARThy, Reparations and Victim Support in the International Criminal Court cit., p. 148. 
Resta-nos saber se a estes requisitos deve somar-se a culpa ou se é possível que haja apenas uma responsabilização civil objetiva.

Após uma análise preliminar, constatamos que alguma doutrina não elenca a culpa como um dos elementos cumulativos a ser comprovado para que a indemnização possa ser atribuída às vítimas ${ }^{40}$.

Fazendo uma interpretação que apele aos elementos literal e sistemático do Estatuto de Roma, constatamos que o n. ${ }^{\circ} 2$ do artigo $75 .^{\circ}$ prevê que "o Tribunal poderá lavrar despacho contra a pessoa condenada, no qual determinará a reparação adequada a ser atribuída as vítimas ou aos titulares de tal direito (...)".

Sendo vários os preceitos que dizem respeito à culpa em sede de responsabilização penal do arguido, o artigo $66 .^{\circ}$ do Estatuto de Roma vem prever o princípio da presunção de inocência que não deixa qualquer margem para dúvidas sobre o carácter subjetivo da responsabilização penal, como aliás não poderia deixar de ser atenta a dignidade da pessoa humana.

Por isso, após a comprovação da prática de um crime, será necessário verificar se se originaram danos às vítimas e se existe um nexo de causalidade entre o facto e o dano para que o Tribunal possa igualmente condenar o arguido à reparação desses danos. Por conseguinte, a partir do momento em que esteja fundada a responsabilização criminal, necessariamente dependente de culpa, poderá desencadear-se a responsabilização civil que assentará naquele delito culposo. É certo que entre a culpa criminal e a culpa civil existem diferenças que não poderão ser escamoteadas, sobretudo ao nível interno, mas poderemos preliminarmente e em virtude da interpretação efetuada afirmar que a responsabilização civil de que se fala não será objetiva.

40 Encontram-se neste rol Conor McCARThy, Reparations and Victim Support in the International Criminal Court cit., p. 134-156, Georghios M. PIKIS, The Rome Statute for the International Criminal Court cit., p. 277-305, William A. Shabas, An introduction to the International Criminal Court cit., p. 361-362, Anne-Marie de Brouwer e Marc Groenhuijsen, "The role of victims in international proceedings", in International Crime Procedure: towards a coherent body of Law, Reino Unido, Cameron May, 2009, p. 187-203 e Marc GroeNHUIJSEn, "Victim's rights and the International Criminal Court: the model of the Rome Statute and its operation", in Hage Joint Conference, 2007, p. 300$315 \mathrm{ou}$, ainda, Paula Vega González, "O papel das vítimas nos procedimentos perante o Tribunal Penal Internacional (...)” cit., p. 28-29. 
O n. ${ }^{\circ} 1$ do artigo $75 .^{\circ}$ do Estatuto de Roma prevê que “(...) o Tribunal poderá, de ofício ou por requerimento, em circunstâncias excecionais, determinar a extensão e o nível dos danos, da perda ou do prejuízo causados às vítimas ou aos titulares do direito a reparação, com a indicação dos princípios nos quais fundamentou a sua decisão". E o n. ${ }^{\circ}$ 2 determina que “(...) esta reparação poderá, nomeadamente, assumir a forma de restituição, indemnização ou reabilitação (...)”. Nos termos do artigo 94. ${ }^{\circ}$ das Regras de Procedimento e Prova, as vítimas que pretendam fazer valer o seu direito à reparação devem apresentar um requerimento escrito ao Secretário do TPI.

Paula Vega González entende que o Tribunal deverá atender aos "Princípios e diretrizes básicas sobre o direito a recurso e reparação para vítimas de violações flagrantes das normas internacionais de Direitos Humanos e de violações graves do Direito Internacional Humanitário"41 quando visar estabelecer os princípios aplicáveis às formas de reparação que venha a ser atribuída às vítimas, nos termos do $n .^{\circ} 1$ do artigo $75 .^{\circ}$ do Estatuto de Roma. Também Marc Groenhuijsen faz apelo a esses princípios quando se reporta ao direito à reparação ${ }^{42}$, assim como o faz, de modo exaustivo, Conor McCarthy ${ }^{43}$.

Segundo o artigo 18. ${ }^{\circ}$ da Resolução 60/147 da Assembleia Geral, a reparação pelo dano sofrido pode efetivar-se de cinco modos diferentes: através da restituição, da compensação, da reabilitação, da satisfação e da outorga de garantias de não repetição, todas elas especificadas nos artigos subsequentes.

A restituição visa reposicionar a vítima na situação em que estaria não fora a prática do facto. A compensação, para efeitos da referida Resolução, abarca tanto os danos patrimoniais como os não patrimoniais. Segundo o seu artigo 20. ${ }^{\circ}$, incluem-se danos à integridade física ou psíquica, perda de oportunidades, danos materiais (dano emergente e lucro cessante), danos morais, despesas médicas, medicamentosas ou

41 Aprovados a 16 de Dezembro de 2005 pela Resolução 60/147 da Assembleia Geral.

42 Marc Groenhuijsen, "Victim's rights and the International Criminal Court" cit., p. 305.

43 Conor McCarthy, Reparations and Victim Support in the International Criminal Court cit., p. 158-183. 
com assistência jurídica. A reabilitação implica a concessão de cuidados médicos e psicológicos às vítimas. Por sua vez, a satisfação inclui, entre outros, um pedido público de desculpas abarcando o reconhecimento do facto cometido e a aceitação da responsabilidade, a concessão de tributos às vítimas ou uma declaração oficial ou judicial com vista à restauração da dignidade, reputação ou direitos da vítima. Por último, a concessão de garantias de não repetição vem prevista no artigo $23 .^{\circ}$ do mesmo instrumento, o que inclui medidas preventivas como a garantia de forças de controlo militar, o reforço da independência dos meios judiciários ou a proteção de quem exerça funções médicas, jurídicas, no âmbito da comunicação social ou defensores dos direitos humanos, entre outros.

Por isso, e como salienta Marc Groenhuijsen, o conceito de "reparação" surge com um âmbito de abrangência mais extenso do que a tradicional indemnização/compensação pela via monetária, devendo pois ser entendido como um conceito expandido ${ }^{44}$.

A referência à específica necessidade de reparação à qual o Estatuto de Roma procura dar a maior cobertura possível pecaria por lapso se não se referisse o Fundo a favor das vítimas, previsto no seu artigo $79 .^{\circ}$, bem como no artigo 98. ${ }^{\circ}$ das Regras de Procedimento e Prova. Segundo resulta da última previsão, as multas pagas pelos condenados podem reverter a favor deste Fundo que procura recolocar as vítimas, tanto como possível, na situação em que estariam caso não tivessem sofrido os crimes sobre elas cometidos - os quais, obviamente, pela sua natureza desde logo impedem que algum dia possam voltar ao ponto em que se encontravam antes de serem brutalmente violentadas. Antes de terem sido queimadas, violadas ou mutiladas, ou ainda de terem visto morrer à sua frente os seus ascendentes ou descendentes.

Perante as atrocidades que o homem (com minúscula intencional) possa cometer perante outro Homem ou Mulher, perante a impossibilidade absoluta de erradicar das mentes e corpos dos sobreviventes as mágoas que os marcam como ferros em brasa, ao menos que sejam envidados todos os esforços possíveis para minimizar essa dor.

44 Marc Groenhuijsen, "Victim's rights and the International Criminal Court" cit., p. 305. 
Neste contexto, e numa procura de restaurar vidas cortadas a eito, foi criado o Fundo supra referido que visará não apenas a atribuição de uma mera compensação às vítimas de tais crimes inqualificáveis pela Humanidade, pois que cometidos ao seu arrepio, mas sim de um conjunto de mecanismos que, com o auxílio direto de comunidades locais, possam auxiliar as vítimas a realizarem cirurgias, a receber próteses, a frequentar a escola ou a reinserir-se nas suas comunidades de onde tinham sido brutalmente arrancadas.

O referido Fundo foi criado por Resolução da Assembleia dos Estados Partes tendo, a 3 de Dezembro de 2005, sido criado o seu Regulamento ${ }^{45}$, segundo o qual os recursos deste Fundo devem ser utilizados a favor das vítimas ${ }^{46}$ de crimes sob a jurisdição do TPI, bem como das suas famílias, de modo a providenciar pela sua reabilitação física ou psíquica, bem como concedendo-lhes apoio material, devendo para tanto o Conselho de Administração notificar o TPI da sua decisão de prosseguir essas atividades (artigo 50. ${ }^{\circ}$ deste Regulamento).

\section{Direito À PROTEÇÃo}

O Estatuto de Roma prevê igualmente um amplo direito à proteção de vítimas e testemunhas, seja na fase do inquérito ou em qualquer fase do julgamento. De facto, o seu artigo $68 .^{\circ}$ estatui que o tribunal deva assegurar a segurança, bem-estar físico e psíquico, dignidade e privacidade das vítimas e testemunhas, devendo atender a diversos fatores como a idade, sexo, estado de saúde, bem como à natureza do crime, pelo que o tipo e grau de proteção serão dependentes destas variáveis ${ }^{47}$.

45 Disponível em http://www.trustfundforvictims.org/sites/default/files/ imce/ICC-ASP-ASP4-Res-03-ENG.pdf, acedido pela última vez a 9 de Março de 2020. Atente-se ainda ao disposto nos artigos $21 .^{\circ}$ e ss. a propósito do financiamento deste Fundo que irá desde contribuições governamentais voluntárias, ou de organizações internacionais, pessoas singulares ou pessoas coletivas, transferências do valor pago a título de multas ao TPI, entre outros. Incluindo pessoas singulares ou coletivas, segundo o disposto no artigo $85 .^{\circ}$ das Regras de Procedimento e Prova.

47 Michael J. Kelly, "The Status of Victims Under the Rome Statute of the International Criminal Court", in Victims of International Crimes: An 
Apesar de todos os órgãos do TPI deverem levar a segurança das vítimas em consideração, saliente-se que esta é especialmente assegurada pela Unidade de Proteção das Vítimas e Testemunhas que, de acordo com o artigo $43 .^{\circ}$, n. 6 do Estatuto de Roma, foi criada pela Secretaria, devendo prestar-lhes aconselhamento e auxiliá-las nomeadamente caso corram algum risco aquando da sua intervenção processual.

Devem ser ainda levadas em consideração as necessidades das vítimas em termos de apoio médico e psicológico e encetadas negociações com os Estados de origem das vítimas e testemunhas traumatizadas ou ameaçadas relativamente às medidas de proteção que devam ser tomadas (atente-se, nomeadamente, ao artigo 87 das Regras de Procedimento e Prova do Tribunal Penal Internacional). Atente-se ainda a uma relevante medida protecionista que se prende com o auxílio que poderá ser dado às vítimas que necessitem de mudar de hábitos de vida para se sentirem devidamente salvaguardadas ${ }^{48}$.

São diversas as medidas que podem ser tomadas em prol das vítimas e testemunhas, bem como dos seus familiares, durante a fase do inquérito e das audiências perante o tribunal, desde e.g. a proteção da sua identidade, podendo inclusive usar um pseudónimo, a possibilidade de o julgamento decorrer à porta fechada ou poderem ser ouvidas através de videoconferência ${ }^{49}$.

Refira-se ainda que, nos termos do referido artigo $68^{\circ}$ do Estatuto de Roma, caso a segurança de vítimas e/ou testemunhas esteja em risco, o tribunal poderá retirar provas ou informações do processo de modo

Interdisciplinary Discourse, ed. por Thorsten Bonacker e Christoph Safferling, Haia, Springer, 2013, p. 57 e ACIDH, Protection des victimes devant la Cour Pénale Internationale, Lubumbashi, Avril de 2011, p. 10, disponível em http:// www.iccnow.org/documents/Brochure_protection_des_victimes_et_t\%E9moins_devant_la_CPI.pdf, acedido pela última vez a 9 de Março de 2020.

48 Michael J. Kelly, "The Status of Victims Under the Rome Statute of the International Criminal Court" cit., p. 56-57 e ACIDH, Protection des victimes devant la Cour Pénale Internationale cit., p. 11-12.

49 ACIDH, Protection des victimes devant la Cour Pénale Internationale cit., p. 11 e 13-15, igualmente referido e.g. por Michael J. Kelly, "The Status of Victims Under the Rome Statute of the International Criminal Court" cit., p. 57 e Marc GroenhuiJsen, "International protocols on victims' rights (...)” cit., p. 24-25 da versão disponível online. 
a salvaguardá-las o que, naturalmente, deverá ser feito com a devida prudência e apenas em casos mais graves para não colocar em causa $o$ direito do arguido a um julgamento justo onde possa conhecer e refutar as provas carreadas para o processo ${ }^{50}$.

Em conclusão, a entrada em vigor do Estatuto de Roma acaba por se revelar como um marco na história da vitimologia, como denotam Marc Groenhuijsen e Rianne Letschert, na medida em que veio incrementar a esfera de proteção a ser concedida à vítima, bem como os seus direitos à participação e à reparação, indo pois para além não só dos estatutos dos tribunais penais internacionais ad hoc que lhe serviram de base, mas também do disposto em diversos sistemas nacionais - quer pertençam, e.g., à família jurídica da common law ou à de direito românico-germânico.

A isto se acrescenta uma relevante medida que visa o tratamento adequado das vítimas de crimes, prevenindo-se ainda a vitimização secundária, a qual consiste no especial cuidado em termos de recrutamento do pessoal para exercer funções junto do Tribunal Penal Internacional, dando-se por exemplo primazia a quem tenha especiais conhecimentos nesta matéria, nomeadamente em termos de crimes de natureza sexual ${ }^{51}$.

Concordamos, pois, com a doutrina no sentido de que o modelo encontrado no Estatuto de Roma deva servir de paradigma aos diversos legisladores nacionais no que se prende à necessidade de tutela e reconhecimento das vítimas nos respetivos enquadramentos jurídico-penais ${ }^{52}$.

50 Michael J. Kelly, "The Status of Victims under the Rome Statute of the International Criminal Court” cit., p. 57-58.

51 Marc Groenhuijsen e Rianne Letschert, "Reflections on the development and legal status of victims' rights instruments", in Compilation of International Victim's Rights Instruments, Outubro, 2006, p. 14 e 15, disponível em https:// pure.uvt.nl/portal/files/804949/REFLECTI.PDF, acedido pela última vez a 9 de Março de 2020.

52 Jan van Dijk e Jo-Anne Wemmers, "Services and rights for victims of domestic and international crimes”, s/d, p. 38, disponível em http://arno. uvt.nl/show.cgi?fid=113651, acedido pela última vez em Julho de 2012 e, atualmente, apenas o respetivo sumário em https://www.researchgate. net/publication/239842913_Victimology_Services_and_rights_for_victims_of_domestic_and_international_crimes, acedido pela última vez a 9 de Março de 2020. 


\section{Considerações finais}

Em jeito de conclusão, será de referir que a doutrina tem reforçado a existência de um conjunto de direitos das vítimas que podem ser transversalmente encontrados em diversos instrumentos de direito internacional, como por exemplo na Declaração sobre Princípios Básicos de Justiça para as Vítima de Crimes e de Abuso de Poder de 1985 ou na Recomendação do Conselho da Europa sobre a posição da vítima no âmbito do Direito Penal e Processual Penal, do mesmo ano, sem esquecer a Decisão-quadro da União Europeia de 2001, entretanto substituída pela Diretiva de 2012 e, ainda, a Recomendação do Conselho da Europa sobre Assistência às vítimas de crimes, de 2006.

Rianne Letschert entende que esses direitos serão, pois, “o direito ao respeito e ao reconhecimento em todas as etapas do processo penal, o direito a receber informação sobre o progresso do caso, o direito de fornecer informação aos responsáveis por tomar decisões relativamente ao agente, o direito a ter apoio jurídico, independentemente dos meios da vítima (...), o direito à proteção da privacidade da vítima e à sua integridade física, o direito à compensação por parte do agressor e do Estado, o direito a receber apoio, o direito a que os Governos tentem promover a mediação em processo penal relativamente aos crimes que considerem apropriados para este tipo de medida e o direito a que o Estado adote, desenvolva e aperfeiçoe a cooperação com Estados estrangeiros nos casos de vitimização para além das fronteiras, de modo a facilitar uma proteção mais efetiva dos interesses das vítimas nos processos penais" 53 .

Conclui-se, assim, que os diversos instrumentos citados revelam uma efetiva preocupação - crescente - para com a vítima de crimes em termos de tutela, necessidades e direitos. Por conseguinte, e em conjunto com os direitos à reparação, à participação e à proteção constantes do Estatuto de Roma, poderão complementar os sistemas processuais penais

53 Rianne Letschert, "International Initiatives and Activities Focusing Specifically on Victims of Terrorism, Including Existing International Instruments" cit., p. 32. 
internos sem, no entanto, ser necessário proceder a uma reforma de fundo que afete a sua estrutura e princípios fundamentais ${ }^{54}$.

E assim se unem dois Mundos aparentemente opostos, para muitos tidos como impassíveis de compaginação, o que se revela claramente possível quando o objetivo nos encaminha para um patamar supremo: in casu, o da procura da tutela efetiva dos direitos daquelas que são, de facto, as principais afetadas pelo crime e que, certo dia, se viram expurgadas de um conflito que é realmente o seu ${ }^{55}$.

\section{REFERÊNCIAS BIBLIOGRÁFICAS}

ACIDH. Protection des victimes devant la Cour Pénale Internationale, Lubumbashi, 2011.Disponível em http://www.iccnow.org/documents/Brochure_protection_des_victimes_et_t\%E9moins_devant_la_CPI.pdf

BITTI, Gilbert. "As vítimas perante o Tribunal Penal Internacional. Participação no processo". Actas da Conferência Internacional de Processo Penal, "Os desafios do Séc. XXI”, Macau, Centro de Estudos Jurídicos e Judiciários, 2007. p. 329-352.

BROUWER, Anne-Marie de e GROENHUIJSEN, Marc. "The role of victims in international proceedings". International Criminal Procedure: towards a coherent body of Law, Londres: Cameron May, 2009. p. 187-203.

CHRISTIE, Nils. "Conflicts of Property". The British Journal of Criminology, vol. 17, n. ${ }^{\circ}$ 1, Janeiro de 1977. p. 1-15.

DIJK, Jan van e WEMMERS, Jo-Anne. "Services and rights for victims of domestic and international crimes". s/d, p. 38, disponível em https://www.researchgate.net/

54 Para mais desenvolvimentos sobre a temática das vítimas em sede processual penal, vide: EduARDo Bolsoni Riboli, "Um "tribunal orientado para a vítima": o minimalismo de Nils Christie e as suas contribuições à justiça restaurativa", in Revista Brasileira de Direito Processual Penal, v. 5, n. 1, 2009, EnRIQue Letelier Loyola, "Editorial del Dossier"Medios alternativos, consensos y la participación de la víctima en el proceso penal: Participación de la víctima en la solución del conflicto penal", in Revista Brasileira de Direito Processual Penal, v. 5, n. 1, 2009 e AAVV, O lugar da vítima nas ciências criminais, Editado por Eduardo Saad-Diniz, São Paulo, LiberArs, 2017.

55 Nils Christie, "Conflicts of Property", The British Journal of Criminology, vol. 17, n. ${ }^{\circ}$ 1, Janeiro de 1977, p. 1-15. 
publication/239842913_Victimology_Services_and_rights_for_victims_of_domestic_and_international_crimes

ESTEVES, Maria Leonor. "A vítima - da quase "invisibilidade” à obtenção de um "Estatuto". Ou do (inevitável) caminho para a humanização da ordem jurídico-penal". Texto apresentado na Conferência organizada pela CIIDH - Escola de Direito da Universidade do Minho, sob o tema "Novos desafios em torno da proteção da vítima: uma perspetiva multidisciplinar”, 2 de Junho de 2017.

GARKAWE, Sam. "Have recent changes designed to benefit victims of international crimes added to the legitimacy of international criminal justice?". International Criminal Justice. Legitimacy and Coherence, Cheltenham e Northampton, Editora Edwar Elgar, 2012. p. 269-303.

GONZÁLEZ, Paulina Vega. "O papel das vítimas nos procedimentos perante o Tribunal Penal Internacional: seus direitos e as primeiras decisões do Tribunal". Revista Internacional de Direitos Humanos, vol. 3 , n. ${ }^{\circ}$ 5, São Paulo, Dezembro 2006, p. 18-41.

GROENHUIJSEN, Marc. “Victim's rights and the International Criminal Court: the model of the Rome Statute and its operation”. Hage Joint Conference, 2007. p. 300-315.

GROENHUIJSEN, Marc e LETSHERT, Rianne. "Reflections on the development and legal status of victim's rights instruments". Compilation of International Victim's Rights Instruments, Outubro, 2006.

JERIN, Robert A. e MORIARTY, Laura J.. The Victims of Crime, New Jersey, Pearson, 2010.

KELLY, Michael J.. "The Status of Victims Under the Rome Statute of the International Criminal Court". Victims of International Crimes: An Interdisciplinary Discourse, ed. por Thorsten Bonacker e Christoph Safferling, Haia, Springer, 2013.

LETELIER LOYOLA, Enrique. Editorial del Dossier "Medios alternativos, consensos y la participación de la víctima en el proceso penal": Participación de la víctima en la solución del conflicto penal. Revista Brasileira de Direito Processual Penal, Porto alegre, vol. 5, n. 1, p. 13-32, jan./abr. 2019. https://doi.org/10.22197/ rbdpp.v5i1.224

LETSCHERT, Rianne. "International Initiatives and Activities Focusing Specifically on Victims of Terrorism, Including Existing International Instruments". In: LETSCHERT, Rianne, STAIGER, Ines e PEMBERTON, Antony (Org.). Assisting Victims of Terrorism., Nova Iorque: Springer, 2010. p. 31-71. 
McCARTHY, Conor. Reparations and Victim Support in the International Criminal Court. Cambridge: Cambridge University Press, 2012.

MOFFETT, Luke. "Releasing Justice for victims before the International Criminal Court”. ICD Brief 6, September 2014.

PIKIS, Georghios M.. The Rome Statute for the International Criminal Court - analysis of the Statute, the Rules of Procedure and Evidence, the Regulations of the Court and supplementary instruments. Leiden, Boston: Martinus Nijhoff Publishers, 2010.

RIBOLI, Eduardo Bolsoni. Um “tribunal orientado para a vítima”: o minimalismo de Nils Christie e as suas contribuições à justiça restaurativa. Revista Brasileira de Direito Processual Penal, Porto Alegre, vol. 5, n. 1, p. 253-298, jan./abr. 2019. https://doi.org/10.22197/rbdpp.v5i1.203

ROBALO, Teresa Lancry A. S.. "Vítimas de terrorismo e justiça restaurativa - análise da questão tendo a Lei n. ${ }^{0}$ 3/2006 sobre a prevenção do terrorismo (Macau) em consideração".Em vias de publicação, 2019.

ROBALO, Teresa Lancry A. S. Justiça Restaurativa. Um Caminho para a Humanização do Direito. Lisboa: Juruá, 2012.

SAAD-DINIZ, Eduardo. O lugar da vítima nas ciências criminais, São Paulo: LiberArs, 2017.

SCHABAS, William A.. An Introduction to the International Criminal Court, $4 .^{\mathrm{a}}$ edição. Cambridge: Cambridge University Press, 2011.

UNODC, E4J University modules.Disponível em https://www.unodc.org/e4j/ en/crime-prevention-criminal-justice/module-11/key-issues/8--victims-ofcrime-and-international-law.html 


\section{Informações adicionais e declarações dos autores (integridade cientifica)}

Declaração de conflito de interesses (conflict of interest declaration): a autora confirma que não há conflitos de interesse na realização das pesquisas expostas e na redação deste artigo.

Declaração de autoria e especificação das contribuições (declaration of authorship): todas e somente as pessoas que atendem os requisitos de autoria deste artigo estão listadas como autores; todos os coautores se responsabilizam integralmente por este trabalho em sua totalidade.

Declaração de ineditismo e originalidade (declaration of originality): a autora assegura que o texto aqui publicado não foi divulgado anteriormente em outro meio e que futura republicação somente se realizará com a indicação expressa da referência desta publicação original; também atesta que não há plágio de terceiros ou autoplágio.

Dados do processo editorial

(http://www.ibraspp.com.br/revista/index.php/RBDPP/about/editorialPolicies)

- Recebido em: 18/03/2020

- Controle preliminar e verificação de plágio: 27/03/2020

- Avaliação 1: 02/04/2020

- Avaliação 2: 23/04/2020

- Decisão editorial preliminar: 03/05/2020

- Retorno rodada de correções: 28/05/2020

- Decisão editorial final: 08/06/2020
Equipe editorial envolvida

- Editor-chefe: 1 (VGV)

- Revisores: 2 
COMO CITAR ESTE ARTIGO:

ROBALO, Teresa Lancry. A vítima de crimes e o Tribunal Penal Internacional: um modelo irrefutável para o legislador interno. Revista Brasileira de Direito Processual Penal, Porto Alegre, vol. 6, n. 3, p. 1417-1444, set./dez. 2020. https://doi.org/10.22197/rbdpp.v6i3.349

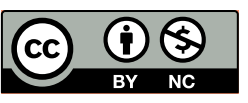

Esta obra está licenciada com uma Licença Creative Commons Atribuição-NãoComercial 4.0 Internacional. 